\title{
Produção e germinação de sementes de "capim dourado", Syngonanthus nitens (Bong.) Ruhland (Eriocaulaceae): implicações para o manejo
}

\author{
Isabel Belloni Schmidt ${ }^{1,2,3,7}$, Isabel Benedetti Figueiredo ${ }^{1,2}$, Fabian Borghetti ${ }^{4}$ e Aldicir Scariot ${ }^{5,6}$
}

Recebido em 27/01/2006. Aceito em 23/04/2007

\begin{abstract}
RESUMO - (Produção e germinação de sementes de “capim dourado", Syngonanthus nitens (Bong.) Ruhland (Eriocaulaceae): implicações para o manejo). A venda de artesanato feito com escapos de S. nitens é uma importante fonte de renda na região do Jalapão, TO. Conhecer a época de produção e dispersão das sementes, bem como seu potencial germinativo, é essencial para propor formas de manejo que garantam a sustentabilidade econômica e ecológica deste extrativismo. Com o intuito de caracterizar a época de produção de sementes foram coletados capítulos entre agosto e dezembro/2003. Foram realizados experimentos de germinação em câmara a $22-30{ }^{\circ} \mathrm{C}$, sob foto e termoperíodo de 12 horas, e também em condições de escuro. Caracterizou-se também a germinação em condições de hipóxia (imersão em água) e acidez (pH 4 e 5). A produção de sementes iniciou-se em setembro e a maior parte da dispersão ocorreu entre outubro e novembro. A germinação das sementes coletadas entre setembro e outubro foi de $92 \pm 7 \%$ (média \pm DP), sementes coletadas a partir de novembro tiveram germinação significativamente menor. A acidez e a hipóxia não afetaram negativamente a germinação em relação ao controle. As sementes são fotoblásticas positivas e mantêm a germinação após congelamento a $-20{ }^{\circ} \mathrm{C}$. A colheita de escapos após a frutificação (a partir do final de setembro) e a dispersão manual das sementes pelos próprios extrativistas no momento da colheita são estratégias importantes para o manejo da espécie e não prejudicam a atividade artesanal que está focada nos escapos e não nas flores, como ocorre para outras sempre-vivas.
\end{abstract}

Palavras-chave: extrativismo vegetal, sempre-vivas, campos úmidos, Cerrado, produtos florestais não madeireiros

\begin{abstract}
Production and germination of "capim dourado" seeds, Syngonanthus nitens (Bong.) Ruhland (Eriocaulaceae): implications for management). The sale of handcraft made from $S$. nitens' scapes is an important source of income in the Jalapão region, Tocantins state. Understanding seed production and dispersal periods, and germination potential is essential to management strategies that guarantee the ecological and economic sustainability of this activity. To characterize the seed production period, capitula were collected from August to December 2003. Germination experiments were conducted in a germination chamber at $22-30{ }^{\circ} \mathrm{C}$, under white light (12-hour photoperiod) and darkness. Germination was also studied under conditions of hypoxia and acidity (pH 4 and 5). Seed production began in September and most dispersal occurred from October to November. The germination of seeds collected in September and October was $92 \pm 7 \%(\mathrm{~m} \pm \mathrm{SD})$. Seeds collected after November had significantly lower germination capacity. Acidity and hypoxia did not affect seed germination. The seeds are positive photoblastic and maintain high germination even after freezing $\left(-20{ }^{\circ} \mathrm{C}\right)$. Harvesting and manual seed dispersal by the harvesters just after harvesting are important management strategies to guarantee the sustainability of this important economic activity and have no negative impact on handcraft activity, which is based on the use of scapes and not flowers.
\end{abstract}

Key words: harvesting, everlasting flowers, Cerrado, humid grasslands, non-timber forest products - NTFP

\section{Introdução}

As "sempre-vivas" são plantas das famílias Eriocaulaceae, Xyridaceae e Poaceae, muito utilizadas na decoração de interiores e confecção de artesanato (Giulietti et al. 1996; Giulietti et al. 1988). O extrativismo destas espécies gera emprego e renda em diversas regiões brasileiras (Giulietti et al. 1988). A grande importância social e econômica contrasta com o pouco conhecimento científico sobre a biologia das sempre-vivas (Sano 1996), e especialmente os efeitos do extrativismo sobre estas populações.

\footnotetext{
1 Programa de Pós-Graduação em Ecologia, Universidade de Brasília, C. Postal 04457, 70910-900 Brasília, DF, Brasil

2 PEQUI - Pesquisa e Conservação do Cerrado, SCLN 113, Bloco B, sala 109, 70763-520 Brasília, DF, Brasil

Diretoria de Florestas Ibama, SCEN Trecho 2, Ed. Sede do Ibama, 70818-900 Brasília, DF, Brasil

4 Universidade de Brasília, Departamento de Botânica, Laboratório de Termobiologia L.G. Labouriau, C. Postal 04573, $70910-900$ Brasília, DF, Brasil

5 PNUD - Programa das Nações Unidas para o Desenvolvimento, SCN Quadra 2, Bloco A, Ed. Corporate Financial Center, $7^{\circ}$ andar, 70712-901 Brasília, DF, Brasil

${ }^{6}$ Laboratório de Ecologia e Conservação, Embrapa Recursos Genéticos e Biotecnologia (Cenargen), Parque Estação Biológica, final W5 Norte, C. Postal 02372, 70770-900 Brasília, DF, Brasil

7 Autor para correspondência: isabelbs@yahoo.com
} 
Compreender o ciclo de vida de espécies-alvo de extrativismo constitui um dos primeiros passos para se sugerir técnicas de manejo que contribuam para a sua conservação (Hall \& Bawa 1993). A época de frutificação e dispersão, bem como a germinação das sementes são características fundamentais para demografia de plantas e constituem importante conjunto de informações para a sugestão de técnicas de manejo sustentável (Hall \& Bawa 1993).

Syngonanthus nitens (Bong.) Ruhland (Eriocaulaceae) é uma sempre-viva bastante comum no Brasil Central, sendo característica de campos úmidos adjacentes a veredas e a matas de galeria inundáveis. Os escapos de $S$. nitens são utilizados para confecção de arranjos florais na Cadeia do Espinhaço (MG e BA, localmente conhecido como sedinha) (Giulietti et al. 1988), Chapada dos Veadeiros (GO) e Distrito Federal (C.B.R. Munhoz, dados não publicados) e em outras regiões, como o vale do rio Paranã (GO e TO) e no Jalapão (TO), os escapos são usados para confecção de artesanato.

A região do Jalapão abriga uma das maiores áreas remanescente de Cerrado conservado e a maior área deste bioma no interior de unidades de conservação (UC) de proteção integral (Silva \& Bates 2002). A densidade populacional é de cerca de $0,6 \mathrm{hab} . / \mathrm{km}^{2}$ e a economia da região está baseada na agricultura de subsistência, pecuária extensiva e no artesanato de S. nitens (Seplan 2003a). O artesanato confeccionado com escapos de $S$. nitens (localmente chamado de capim dourado) costurados com "seda" de buriti (fibra da folha flecha de Mauritia flexuosa Mart., Arecaceae) é tradicional na região há cerca de 80 anos, mas passou a ser economicamente importante a partir do princípio dos anos 2000. Atualmente, o extrativismo de $S$. nitens ocorre no interior e entorno das UC. A possibilidade de obtenção de renda a partir do artesanato provocou incremento significativo no número de artesãos e na pressão de coleta sobre as espécies utilizadas (Schmidt 2005).

Identificar e implementar formas de manejo que contribuam para a sustentabilidade econômica e ecológica desta espécie são ações essenciais para garantir a efetividade destas unidades em promover a conservação de áreas naturais no Jalapão. Como parte deste esforço, este trabalho teve por objetivo identificar o período de produção e dispersão de sementes de $S$. nitens; caracterizar a germinação das sementes e testá-la em condições semelhantes às ocorrentes em campos úmidos.

\section{Material e métodos}

Espécie estudada - Os indivíduos de Syngonanthus nitens apresentam roseta basal de folhas pouco pilosas, lineares a oblongas, com $1 \mathrm{a} 4 \mathrm{~cm}$ de comprimento e 0,1 a $0,2 \mathrm{~cm}$ de largura, de onde podem partir de 1 a 10 escapos terminais glabros. As inflorescências têm forma de capítulos e apresentam brácteas involucrais creme brilhantes que, junto com os escapos dourados caracterizam a espécie (Giulietti et al. 1996). A espécie é policárpica, os indivíduos podem atingir a maturidade sexual no primeiro ano de vida. A produção de escapos no Jalapão inicia-se entre abril e maio e a floração ocorre a partir de julho (Schmidt 2005). Além da reprodução sexuada, a espécie apresenta reprodução clonal, pela rebrota de rosetas por gemas axilares, cerca de $60 \%$ das novas plantas recrutadas em um período de um ano originaram-se por reprodução clonal (Schmidt 2005).

Área de estudo - As sementes utilizadas neste estudo foram coletadas em campos úmidos próximos ao Povoado da Mumbuca, município de Mateiros, TO (10²1'97'S; 46³4'91'W). A área caracteriza-se por solo de areia quartzosa, em que ocorrem predominantemente campos sujos e cerrado sentido restrito. As vastas extensões de cerrado são cortadas por pequenos cursos d'água ao longo dos quais ocorrem matas de galeria, geralmente inundáveis, caracterizadas pela presença abundante de buriti (Mauritia flexuosa). Adjacentes às formações florestais associadas à água, ocorrem campos limpos úmidos, onde o solo é geralmente hidromórfico, mas podendo, em alguns locais, ser bastante arenoso. Nestes campos úmidos, dominados por gramíneas e caracterizados pela presença de espécies de Xyridaceae, Cyperaceae e Eriocaulaceae, ocorre $S$. nitens.

A precipitação média anual no Jalapão é de cerca de $1.700 \mathrm{~mm} / \mathrm{ano}$, concentrada no período de outubro a março, sendo que nos meses de junho a agosto pode não haver precipitação (Seplan 2003b). A temperatura do ar a $40 \mathrm{~cm}$ do solo nos campos úmidos, medida por sensores eletrônicos em aparelhos com unidade de armazenamento de dados (HOBO $®)$ por sete dias no mês de agosto, pode variar em um mesmo dia de 13 a $40{ }^{\circ} \mathrm{C}$.

Material coletado e experimentos de germinação Para biometria, sementes foram retiradas dos capítulos com o auxílio de lupa (Zeiss, modelo Stemi SV 11), sendo que 500 sementes (cinco repetições de 100 sementes) foram pesadas em balança de precisão (marca Ohaus, acurácia de 0,001 g) para o cálculo da 
massa fresca aproximada de cada semente. Cem sementes foram medidas com auxílio de escala inframilimétrica acoplada à lupa.

Para caracterizar a época de produção e dispersão de sementes de $S$. nitens, foram coletados capítulos em três campos úmidos, quinzenalmente, entre 20 de agosto e 20 de dezembro/2003. Após a coleta, os capítulos foram armazenados em sacos de papel, a temperatura ambiente. Capítulos coletados em uma mesma data foram agrupados em lotes para realização dos experimentos. Os capítulos foram examinados em laboratório com auxílio de lupa para contagem de sementes ( $\mathrm{n}=15$ capítulos/lote).

Para avaliar a capacidade de germinação por data de coleta, as sementes foram mantidas separadas por lotes e colocadas em placas de Petri com papel de filtro umedecido em água destilada. Foram utilizadas quatro repetições de 50 sementes por lote (total de sete lotes). As sementes foram dispostas em câmara de germinação com temperatura alternada de $22-30{ }^{\circ} \mathrm{C}$ (N/D), em fotoperíodo de 12 horas com luz branca durante o dia. Este regime térmico se encontra na faixa de temperatura na qual a maior parte das sementes nativas estudadas germina, quando não apresentam algum tipo de dormência (Borghetti 2005). Os experimentos foram acompanhados por 60 dias, quando todas as sementes haviam germinado ou apresentavam sinais claros de aprodecimento e morte do embrião. Também foram realizados experimentos de germinação no escuro (observações sob luz verde). Com o intuito de reproduzir em laboratório condições para germinação encontradas no ambiente natural, investigou-se a germinação das sementes em condições de acidez ( $\mathrm{pH}$ 4 e 5 - mantidos com tampão fosfato $0,01 \mathrm{~mol} \mathrm{~L}^{-1}$ ) (C.B.R. Munhoz, dados não publicados); e em condições de hipóxia através da imersão das sementes em água destilada em placas de Petri. A hipóxia pode ser comum em campos úmidos, especialmente no período chuvoso, subseqüente à dispersão de sementes de $S$. nitens. Para os tratamentos escuro, acidez e hipóxia foram utilizadas sementes colhidas em 5 de setembro e 20 de outubro (quatro repetições de 50 sementes/lote), que foram dispostas na câmara de germinação com foto e termoperíodos descritos acima. Visto que a germinação foi semelhante entre estes lotes (ver resultados), os dados foram agrupados para analisar os efeitos dos tratamentos na germinação, perfazendo oito repetições de 50 sementes para cada tratamento.

Para verificar possíveis efeitos do congelamento e descongelamento sobre a germinação das sementes, foi realizado teste de germinação com sementes que foram congeladas a $20^{\circ} \mathrm{C}$ negativos, por três dias $(4 \times$ 50 sementes, lote 5 de setembro). Após o descongelamento as sementes foram dispostas em placas de Petri nas mesmas condições descritas anteriormente.

As porcentagens de germinação das sementes dos diferentes lotes foram comparadas com Análise de Variância (ANOVA). As porcentagens de germinação das sementes submetidas aos diferentes tratamentos foram comparadas com o controle por ANOVA $(\mathrm{pH} 4$ $\times$ pH $5 \times$ controle) e por teste $\mathrm{t}$ (tratamentos de escuro, hipóxia e congelamento versus controle, dois a dois separadamente). Os valores de percentual de germinação foram transformados para arcoseno para a realização das análises para atender as premissas de normalidade de variâncias e homocedasticidade (Zar 1999; Santana \& Ranal 2004).

\section{Resultados}

As sementes de Syngonanthus nitens são oblongas, pesam cerca de $0,033 \pm 0,0007 \mathrm{mg}$, têm entre 0,89 $\pm 0,09 \mathrm{~mm}$ de comprimento e 0,32 $\pm 0,06$ (média \pm DP) de largura, possuem coloração marrom e estrias longitudinais. Estão dispostas no interior dos capítulos, geralmente em pares ligados às brácteas involucrais.

A produção de sementes iniciou-se entre o final de agosto e o princípio de setembro de 2003, uma vez que nos capítulos coletados em 20 de agosto/2003 havia apenas flores e, nos capítulos coletados a partir de 5 de setembro, foram identificadas sementes. Estas sementes apresentaram coloração mais clara que as sementes coletadas em datas subseqüentes. A dispersão ocorreu entre o final do mês de outubro e novembro, período em que o número médio de sementes por capítulo decresceu consideravelmente (Fig. 1).

A germinação das sementes em laboratório iniciou-se a partir do sétimo dia de embebição (Fig. 2). Inicialmente, ocorreu a emissão da radícula e, após 10 a 15 dias, a emissão da primeira folha, seguida por rápida formação de novas folhas e pêlos radiculares. O desenvolvimento pós-seminal ocorreu de forma semelhante em todos os tratamentos. Não houve diferenças significativas entre a porcentagem de germinação das sementes coletadas entre 05 de setembro e 20 de outubro, enquanto que as sementes coletadas a partir de 20 de novembro apresentaram germinação significativamente inferior à dos períodos anteriores (ANOVA $\mathrm{F}_{6,21}=58,808 ; \mathrm{P}<0,001$, seguida 


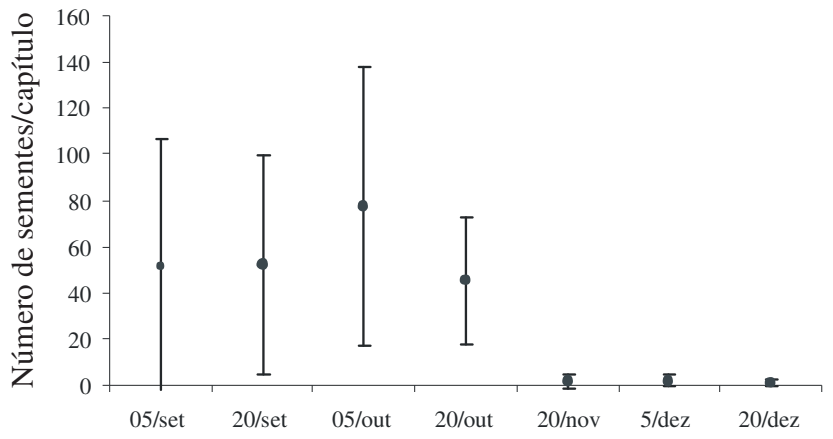

Figura 1. Número médio ( \pm desvio padrão) de sementes de Syngonanthus nitens por capítulo, coletados entre setembro e dezembro/2003 ( $=15$ a 30 capítulos/lote) no município de Mateiros, Tocantins. Houve falha na coleta de 5 de novembro.

de teste Tukey). O experimento foi finalizado após 60 dias, quando todas as sementes não germinadas estavam mortas, o que foi determinado por seu evidente apodrecimento, não tendo sido necessários testes de viabilidade.

A germinação das sementes não foi afetada, em relação ao controle, pelas condições de acidez testadas (ANOVA: $F_{2,21}=0,468, P=0,633$ ). Enquanto que as sementes em hipóxia, apresentaram percentual de germinação mais elevado que as sementes do controle em papel umedecido (teste $t=2,3 ; P=0,036$, Fig. 3). Não houve germinação na ausência de luz, o que indica

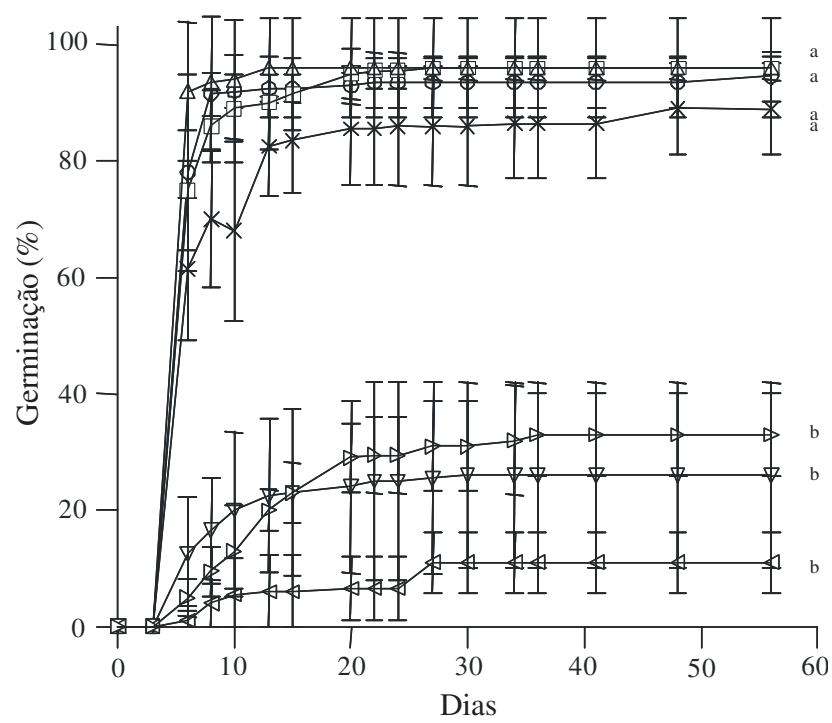

Figura 2. Média de germinação ( \pm desvio padrão) de sementes de Syngonanthus nitens coletadas em diferentes épocas de 2003 no município de Mateiros, Tocantins. Experimento conduzido em câmara de germinação a $22 / 30{ }^{\circ} \mathrm{C}$ com foto e termoperíodo de 12 horas $(\mathrm{n}=4 \times 50$ sementes/lote). Letras diferentes indicam diferenças estatísticas significativas (ANOVA seguida de teste Tukey; $\mathrm{P}<0,05) . \quad(O=5 /$ setembro; $x=20 /$ setembro; $\square=5 /$ outubro; $\triangle=20 /$ outubro $\quad \nabla=20 /$ novembro; $\triangleleft=5 /$ dezembro; $\triangleright=20 /$ dezembro). fotoblastismo positivo da espécie. Após 39 dias sob condições de escuro, as sementes foram expostas à luz branca e germinaram em proporções semelhantes ao controle $(\mathrm{G}=88 \pm 3,5 \%$; teste $\mathrm{t}=1,1 ; \mathrm{P}=0,289)$. Após o congelamento e descongelamento, a porcentagem de germinação das sementes foi semelhante ao controle $(\mathrm{G}=72 \pm 13,5 \%$, teste $\mathrm{t}=2,4$; $\mathrm{P}=0$,052, Fig. 3).

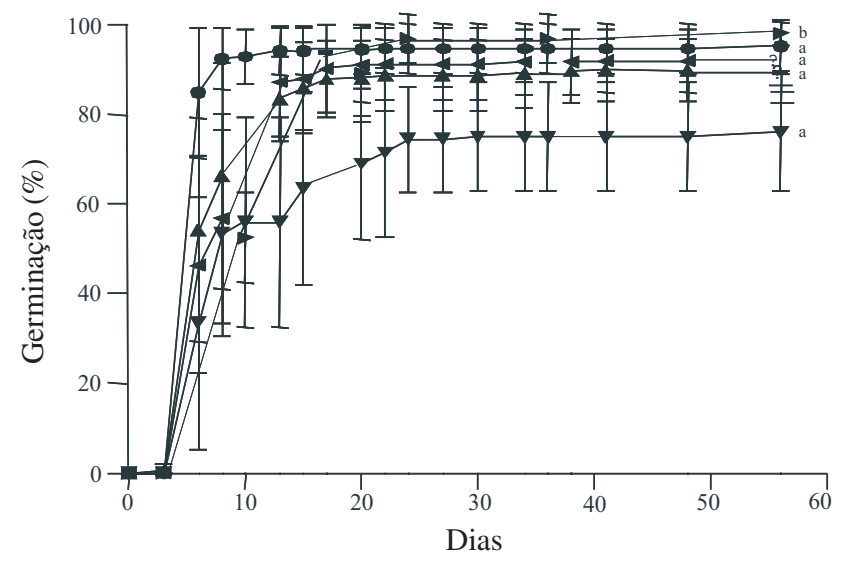

Figura 3. Média de germinação ( \pm desvio padrão) de sementes de Syngonanthus nitens câmara de germinação a $22 / 30^{\circ} \mathrm{C}$ com foto e termoperíodo de 12 horas ( controle) e submetidas a pH 4,0 (४); pH 5,0 (४); imersão em água destilada $(\bullet)(\mathrm{n}=8 \times 50$ sementes/ lote) e a congelamento a $-20{ }^{\circ} \mathrm{C}$ por três dias $(\nabla)(n=4 \times 50$ sementes). Letras diferentes indicam diferenças estatísticas significativas (teste $\mathrm{P}<0,05$ ).

\section{Discussão}

As sementes de $S$. nitens têm alta capacidade de germinação, semelhante ou mais elevada do que o encontrado para outras espécies congêneres (Oliveira \& Garcia 2005; Paixão-Santos et al. 2003; Scatena 1996) e descritas para espécies de Paepalanthus (Kraus et al. 1996). A germinação inicia-se rapidamente em condições de laboratório, desde que haja incidência de luz. A partir do número de sementes encontrado em cada capítulo (média de $60 \pm 14$ sementes/capítulo, mínima de 0 e máxima de 237 sementes/capítulo) e considerando a produção de 1 a 10 escapos por indivíduo (Schmidt 2005), estima-se que cada indivíduo de $S$. nitens produza entre 60 a 2.000 sementes/ano. Esta alta produção de sementes ocorre também em outras Eriocaulaceae, como Paepalanthus polyanthus, uma espécie monocárpica tardia que produz cerca de 9.000 sementes/indivíduo (Castellani \& D'Eça-Neves 2000).

$\mathrm{O}$ alto potencial germinativo das sementes não foi prejudicado pela acidez ou pela hipóxia, condições 
tipicamente encontradas em campos úmidos, especialmente no período chuvoso, logo após a dispersão das sementes. O fotoblastismo positivo, também descrito para outras espécies de Eriocaulaceae (Kraus et al. 1996; Oliveira \& Garcia 2005; Sá e Carvalho \& Ribeiro 1994; Scatena 1996), é comum entre espécies com sementes pequenas (Pons 2000). A exigência por luz reduz a probabilidade de germinação quando as sementes estão soterradas, o que é estratégico para diásporos com reservas limitadas, e limita a germinação às condições de luminosidade (Pons 2000; Zaidan \& Barbedo 2004).

Por se tratarem de sementes pequenas típicas de campos úmidos, a permanência das sementes em condições úmidas e de escuro deve ocorrer bastante freqüentemente. $\mathrm{O}$ fato das sementes manterem a viabilidade e germinabilidade mesmo após mais de um mês de embebição em condições de escuro, indica que $S$. nitens pode formar um banco de sementes transiente, com potencial de recrutamento de novos indivíduos nos primeiros meses durante o período chuvoso, desde que seja satisfeito a exigência por luz. Além disto, a tolerância à acidez e à hipóxia são características que indicam que estas sementes podem manter-se viáveis e germinar em condições naturais no solo dos campos úmidos. A germinação das sementes após congelamento e descongelamento indica que o armazenamento a baixas temperaturas pode ser uma forma de conservação ex situ de germoplasma.

A elevada produção de sementes, seu alto potencial germinativo, inclusive com tolerância das sementes às condições de alagamento e acidez, propiciam o recrutamento de novos indivíduos por sementes em condições naturais. Estas características corroboram a importância das sementes para a demografia desta espécie que apresenta alta capacidade de reprodução vegetativa (Schmidt 2005). Conforme a época em que é feita, a colheita de escapos pode comprometer a produção de sementes. A remoção de grandes quantidades de sementes do ambiente pode reduzir o potencial de recrutamento de novas plântulas afetando a dinâmica populacional da espécie. Giulietti et al. (1996) argumentam que a colheita de escapos na fase de floração pode ser um dos determinantes para as reduções populacionais de sempre-vivas exploradas comercialmente em Minas Gerais e Bahia. A colheita prematura, anterior à maturação dos escapos, pode resultar também em desenraizamento de rosetas, matando indivíduos adultos com potencial reprodutivo.
Um aspecto muito importante do extrativismo para a confecção de artesanato de capim dourado é que os escapos são utilizados, e não as flores, como ocorre na produção de arranjos com outras sempre-vivas, ou mesmo o próprio $S$. nitens na região de Minas Gerais, Bahia e Goiás. Para a confecção de arranjos, os escapos devem ser coletados quando ainda estão em floração, visto que após a produção das sementes, as flores mudam de coloração e conseqüentemente perdem valor comercial (Lúcio C. Bedê, com. pes.). Para o artesanato de $S$. nitens, o interesse está primordialmente voltado para o escapo, cujo brilho aumenta após a secagem, que ocorre após o período de produção de sementes.

A partir da caracterização da época de produção e dispersão de sementes encontradas neste estudo, o Naturatins (Instituto Natureza do Tocantins) passou a regulamentar a colheita de escapos de $S$. nitens no Jalapão (Portarias Naturatins n. 055/2004 e 092/2005). Assim, desde 2004, os escapos só podem ser colhidos após 20 de setembro e os capítulos devem ser cortados e lançados ao solo nos campos úmidos logo após a colheita dos escapos. Justamente pelo fato de o interesse artesanal estar centrado nos escapos e não nas flores de $S$. nitens, a realização da colheita neste período, após a produção das sementes não traz nenhuma desvantagem para a confecção de artesanato de capim dourado. Além disto, não há prejuízo algum na retirada dos capítulos no momento da colheita, uma vez que estes são usados raramente e em pequenas quantidades para a ornamentação das peças e considerando este fato, haverá uma modificação na Portaria que regulamentará a colheita em 2006, permitindo que cada artesão mantenha uma pequena quantidade de escapos com capítulos. O interesse central nos escapos diferencia o extrativismo de $S$. nitens para confecção de artesanato do extrativismo de semprevivas (inclusive de $S$. nitens) para a confecção de arranjos e é um fator chave que poderá possibilitar a sustentabilidade desta atividade.

Os resultados encontrados mostram ser possível uma adequação entre o uso sustentado de $S$. nitens como fonte de renda para comunidades locais no Jalapão e a manutenção das populações naturais nos campos úmidos da região. Para isto, as características de recrutamento da espécie em condições naturais devem ser respeitadas, permitindo a produção e a dispersão de sementes nos campos úmidos, como estabelece a regulamentação existente. 


\section{Agradecimentos}

Aos moradores do Povoado da Mumbuca, especialmente José Ribeiro da Silva, pelo auxílio na coleta de sementes; às equipes do Parque Estadual do Jalapão e da Estação Ecológica Serra Geral do Tocantins pelo apoio logístico e na divulgação dos resultados entre as comunidades locais; ao WWF/Brasil, pelo apoio financeiro (Programa Natureza e Sociedade de apoio a dissertações e teses); a Antonieta Nassif Salomão, Alexandre Bonesso Sampaio e Daniel Mascia Vieira, pelas sugestões no manuscrito.

\section{Referências bibliográficas}

Borghetti, F. 2005. Temperaturas extremas e a germinação das sementes. Pp. 207-218. In: R.J.M.C. Nogueira; E.L. Araújo; L.G. Willadino \& U.M.T. Cavalcante (eds.). Estresses ambientais: danos e benefícios em plantas. Recife, Imprensa Universitária.

Castellani, T.T. \& F.F. D’Eça-Neves. 2000. Population Ecology of Paepalanthus polyanthus: Predispersal hazards and seed production. Acta Botanica Brasilica 14: 317-326.

Giulietti, A.M.; Wanderley, M.G.L.; Longhi-Wagner, H.M.; Pirani, J.R. \& Parra, L.R. 1996. Estudos em "sempre vivas": taxonomia com ênfase nas espécies de Minas Gerais, Brasil. Acta Botanica Brasilica 10: 329-383.

Giulietti, N.; Giulietti, A.M.; Pirani, J.R. \& Menezes, N.L. 1988. Estudos em sempre-vivas: importância econômica do extrativismo em Minas Gerais. Acta Botanica Brasilica 1: 179-193.

Hall, P. \& Bawa, K. 1993. Methods to asses the impact of extraction of non-timber tropical forest products on plant populations. Economic Botany 47: 234-247.

Kraus, J.E.; Scatena, V.L.; Lewinger, M.E. \& Trench, K.U.S. 1996. Morfologia externa e interna de quatro espécies de Paepalanthus Kunth (Eriocaulaceae) em desenvolvimento pós seminal. Boletim de Botânica da Universidade de São Paulo 15: 45-53.
Oliveira, P.G. \& Garcia, Q.S. 2005. Efeitos da luz e da temperatura na germinação de sementes de Syngonanthus elegantulus Rhuland, S. elegans (Bong.) Rhuland e S. venustus Silveira (Eriocaulaceae). Acta Botanica Brasilica 19: 639-645.

Paixão-Santos, J.D.; Dornelles, A.L.C.; Silva, J.R.D.S. \& Rios, A.P. 2003. Germinação in vitro de Syngonanthus mucugensis Giulietti. Sitientibus série Ciências Biológicas 3: 120-124.

Pons, T.L. 2000. Seeds responses to light. Pp. 237-260. In: M. Fenner (ed.). Seeds: the ecology of regeneration in plant communities. $2^{\text {nd }}$ Ed. UK. CABI Publishing.

Sá e Carvalho, C.G. \& Ribeiro, M.C. 1994. Efeitos de choques térmicos na germinação de Paepalanthus speciosus Koern. (Eriocaulaceae). Acta Botanica Brasilica 8: 205-211.

Sano, P. T. 1996. Fenologia de Paepalanthus hilairei Koern., $P$. polyanthus (Bong.) Kuth e P. robustus Silveira: Paepalathus Sect. actinocephalus Koern. Eriocaulaceae. Acta Botanica Brasilica 10: 317-327.

Santana, D.G. \& Ranal, M.A. 2004. Análise estatística. Pp. 197208. In: A.G. Ferreira \& F. Borghetti (eds.). Germinação: do básico ao aplicado. Porto Alegre, Artmed.

Scatena, V.L.; Lemos Filho, J.P. \& Lima, A.A.A. 1996. Morfologia do desenvolvimento pós-seminal de Syngonanthus elegans e $S$. niveus (Eriocaulaceae). Acta Botanica Brasilica 10: 85-91.

Schmidt, I.B. 2005. Etnobotânica e ecologia populacional de Syngonanthus nitens: "sempre-viva" utilizada para artesanato no Jalapão, TO. Programa de Pós-Graduação em Ecologia. Universidade de Brasília, Brasília.

Seplan. 2003a. Plano de Manejo do Parque Estadual do Jalapão. Palmas, TO.

Seplan. 2003b. Zoneamento Ecológico Econômico de Tocantins. www.seplan.to.gov.br.

Silva, J.M.C. \& Bates, J.M. 2002. Biogeographic Patterns and Conservation in the South American Cerrado: A Tropical Savanna Hotspot. BioScience 52: 225-234.

Zaidan, L.B.P. \& Barbedo, C.J. 2004 Quebra de dormência em sementes. Pp. 135-148. In: A.G. Ferreira \& F. Borghetti. Germinação: do básico ao aplicado. Porto Alegre, Artmed.

Zar, J.H. 1999. Biostatistical analysis. New Jersey, Prentice Hall. 